\title{
Rosarium: A four-part collage
}

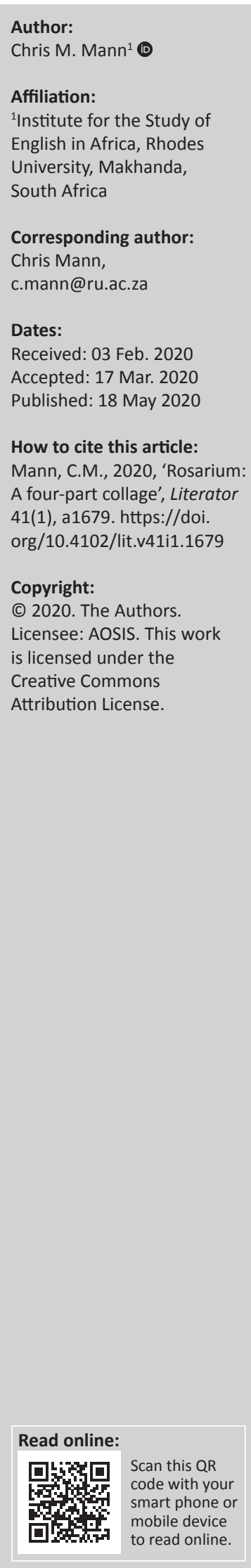

A collage of poems written in different forms that refer to different stages of human life and express different aspects of romantic love using the symbol of a rose.

\section{A fragrance from the past}

Mud and sweat on a rugby field in mist, and then perched on the clothes-heap inside my locker, a crisp clean envelope, its fountain-pen lettering rounded, blue.

My name - in such a handcrafted script? I tore the flap, clumsily, with a finger. Creamy white paper, a fragrant scent, a trelliswork of tiny red buds and leaves.

Edged by their green, the same neat ink. Lots of good luck for the match, it read, and underneath, with curly flourishes, Jenny brackets De Villiers brackets.

De Villiers? De Villiers ... the new boy, the girl he was with, older than him, outside the hall before the school play, was that his sister, is that who it's from?

A pang shot through me. I breathed fast, oblivious to the gibes from the scrumhalf, the changing-room reek of stained urinals, disinfectant, used socks and wintergreen.

Well, nothing much came of that breakout, don't ask me why, except for an epiphany shaped into a memory, a video-in-waiting which, pondered now, seethes into sight

A girl in a blazer, a pale blue skirt, a boater with a ribbon, worn dead level, a turn of the head, a slow-release glance and love's first explosion of fragrance,

green leaves, and red, red roses in the brain.

\section{The bud \\ after John Donne}

The sky's orbed tent of sullied air. The ransacked soil. The littered sea. The rainbow fish charred by the sun ...

Oh purse-lipped bud, if you knew this, would you still blossom on your twig, and let the breeze caress your mouth?

Your tumescence is too tender. Your petals' red bouquet too moist, For mankind's mechanistic touch.

Your beauty's for the bees, not us. Fear the hothouse, the boudoir vase. Evolve more thorns, a dumpsite rose.
Anoint your niche with love's fresh scent, Be prayer unsoiled, a thorned rebuke, A drop transmuted of Christ's blood,

For we transgress where we possess.

\section{To Julia in the supermarket}

Ah strange, distant and beautiful woman, pushing a trolley down an avenue of tins, a child in tow, a shopping list in hand,

How much I adore the curve of your waist, the sway of your body, the pause, the turn and reed-quick bending to one side of you.

Let me pile your trolley with new-baked rolls and fill your arms with artichokes and wine. Let me explain that thinking you elsewhere but finding you here has torn the membrane that custom and routine thickens in my eyes and through the fissure bursts, as at the first, the whole breathing, talking, hurrying, laughing, red-lipped, green-scarfed, warm-hipped woman of you.

\section{The heart stays young}

Guga mzimba, sala inhliziyo.

As the grey-haired father late at night stands and stares at a moonlit bed, remembering, in a rush of love,

Toys on the floor, a sleeping head,

So the body, the body grows old, but the heart, the heart stays young.

As the swallow fleeing the winter's cold,

Weakening, yearns to rest,

But journeys on towards the spring,

Like hunger on a ceaseless quest,

So the body, the body grows old, but the heart, the heart stays young.

As the blemished hand on the folded rug, Trembling tenderly in repose,

Stretches from the frail-care bed

Towards a dark-red, fragrant rose,

So the body, the body grows old,

But the heart, the heart stays young. 